(1)

Klinik Çalışma Original Article

\title{
Kardiyovasküler Hastalık Tanısıyla Yatarak Tedavi Gören Hastaların Illaç Tedavisine Uyumları ve Etkileyen Faktörlerin Değerlendirilmesi
}

\author{
๑ Abdullah Avcı ${ }^{1}, \oplus$ Meral Gün², ๑ Semra Erdoğan ${ }^{3}$ \\ ${ }^{1}$ Mersin Üniversitesi Hastanesi, Kardiyoloji Kliniği, Mersin \\ ${ }^{2}$ Mersin Üniversitesi Hemşirelik Fakültesi, İç Hastalıkları Hemşireliği Anabilim Dalı, Mersin \\ ${ }^{3}$ Mersin Üniversitesi Tıp Fakültesi, Biyoistatistik ve Tıbbi Bilişim Anabilim Dalı, Mersin
}

\begin{abstract}
Özet
Amaç: Bu araştırmada kardiyovasküler hastalık tanısıyla yatarak tedavi gören hastaların ilaç tedavisine uyumları ve etkileyen faktörlerin belirlenmesi amaçlandı.

Yöntemler: Tanımlayıcı nitelikte olan bu araştırma bir üniversite hastanesinin kardiyoloji servisinde kardiyovasküler hastalık tanısı ile yatarak tedavi gören ve en az 3 aydır ilaç kullanan 176 hasta ile gerçekleştirildi. Araştırmanın verileri 13 Haziran-28 Ekim 2016 tarihleri arasında anket formu ve Morisky ilaç tedavisine uyum ölçeği kullanılarak toplandı. İstatistiksel analizler için sayı, yüzdelik, aritmetik ortalama, t-testi, One Way ANOVA, Levene testi, Shapiro Wilk testi ve Pearson korelasyon analizi kullanıldı.

Bulgular: Araştırma kapsamına alınan bireylerin \%51.7'sinin erkek olduğu, çoğunluğunun çalışmadığı, yarısında ilave kronik hastalık olarak diyabet tanısı olduğu, yarıya yakınının beş kez ve üzeri hastaneye yattığı ve yaş ortalamasının $65.39 \pm 7.73$ olduğu belirlendi. Hastaların yarıya yakınının yedi yıl ve üzeri, yarıdan fazlasının ise günde altı ve üzeri sayıda ilaç kullandığı ve ilaç uyum puan ortalamasının 4.78 2 2.03 (düşük düzeyde) olduğu saptandı. Ayrıca hastaların \%40.9'unun reçete dışı ilaç kullandıkları ve reçete dışı ilaç olarak ise en çok analjezik kullandıkları belirlendi. Bu araştırmada hastaların sosyodemografik ve klinik özellikler açısından ilaç tedavisine uyum puan ortalamaları arasında önemli fark bulunmadı ( $\mathrm{p}>0.05$ ). Bu araştırmada hastaların çoğunluğunun ilaçları neden kullandıklarını bilmedikleri (en az bilinenler sırasıyla; kalp glikozitleri \%10.6, beta-blokerleri \%22.2, anjiotensin dönüştürücü enzim inhibitörleri \%26.6) ve çoğunluğunun kullandıkları ilaçların yan etkilerini bilmedikleri (yan etkilerini bilme oranı en az olan ilaç grubu ise sırasıyla; kalp glikozitleri 0\%, beta-bloker \%7.7 ve ACEil \%8.5, diüretikler \%12.1) belirlendi.
\end{abstract}

Sonuç: Bu araştırmada kardiyovasküler hastalık tanısı olan bireylerin yarısının ilaç tedavisine düşük uyum gösterdiği, çoğunluğunun kullandıkları ilaçların etki ve yan etkilerini bilmedikleri tespit edildi.

Anahtar sözcükler: Hemşirelik; ilaç uyumu; kardiyovasküler hastalıklar.

Evulation of Medication Adherence and Affecting Factors in Inpatients with a Diagnosis of Cardiovascular Disease

\section{Abstract}

Objective: In this study it was aimed to determine compliance to medication in patients receiving inpatient treatment due to diagnosis of cardiovascular disease and the affecting factors. 


\begin{abstract}
Methods: The descriptive study was conducted with 176 patients receiving inpatient treatment due to diagnosis of cardiovascular disease in the cardiology service in a university hospital and taking medication for at least 3 months. The study data were collected using the personal information form and Morisky Compliance to Medication Scale between June $13^{\text {th }}$ Occtober $28^{\text {th }}$, 2016. Number, percentage, arithmetic mean, t-test, One Way ANOVA, Levene test, Shapiro Wilk test and Pearson correlation analysis were used for statistical analysis.

Results: It was determined that $51.7 \%$ of individuals who were included in the study were male; majority of them were unemployed; half of them were diagnosed with diabetes as chronic additional disease; nearly half of them had been hospitalized for five times and above; and their age average was 65.39 \pm 7.73 years. It was found that nearly half of the patients used drugs for seven years or more, and more than half used six or more drugs per day and the mean score of the Morisk Medication Compliance Scale was $4.78 \pm 2.03$ (low level). In addition it was determined that $40.9 \%$ of patients took unprescribed medication and they often took analgesics as unprescribed medication. In this study there was no significant difference between mean scores on medication compliance in terms of sociodemographic and clinical characteristics of patients ( $p>0.05$ ). It was also determined that majority of patients did not know why they had to take medication (those known at minimum, respectively; cardiac glycosides $10.6 \%$, beta-blockers $22.2 \%$, angiotensin converting enzyme inhibitors $26.6 \%$ ) and majority of them were not acquainted with the side effects of medications they took (those known at minimum, respectively; cardiac glycosides $0 \%$, beta-blockers $7.7 \%$ and ACEII 8.5\%, diuretics 12.1\%).

Conclusion: In the study it was determined that half of individuals diagnosed with cardiovascular disease showed a lower complicance to treatment and majority of them were not acquainted with the effects and side effects of medications they took. Keywords: Cardiovascular diseases; compliance to medication; nursing.
\end{abstract}

Cite this article as: Avcı A, Gün M, Erdoğan S. Evulation of Medication Adherence and Affecting Factors in Inpatients with a Diagnosis of Cardiovascular Disease. Turk J Cardiovasc Nurs 2020;11 (26):132-139.

$\mathrm{K}_{\mathrm{kach}}^{\mathrm{rot}}$ ronik hastalıklar içerisinde önemli bir yere sahip olan kardiyovasküler hastalıklar (KVH) ülkemizde ve Dünya'da en önemli ölüm nedenleri arasında yer almaktadır. ${ }^{[1,2]}$ İlaç tedavisine uyum hem kardiyosküler risk faktörleri hem de KVH nedeniyle morbidite ve mortaliteyi önemli düzeyde azaltmaktadır. ${ }^{[3,4]}$ illaç uyumu hastaların ilaçlarını sağlık bakım vericilerin önerileri doğrultusunda kullanması olarak ele alınmaktadır. KVH'ın önlenmesi ve kontrolünde statin, antiplatelet, antiagregan, antikoagülan, antiaritmik, beta bloker vb. ilaçların düzenli kullanılması birincil öneme sahiptir. [3,5,6] Kardiyovasküler ilaçların düzenli kullanılması tekrarlı yatışları, hastalıkla ilişkili morbidite ve mortaliteyi dolayısıyla maliyeti önemli düzeyde azaltmaktadır. ${ }^{[5,7-9]}$ Araştırmalarda yetersiz ilaç uyumun kötü sağlık sonuçlarına, tekrarlı hastane yatışlarına ve sağlık harcamalarının artmasına neden olduğu ilaç kullanımına uyumun artmasıyla ise tekrarlı yatışların ve maliyetin azaldığı belirtilmektedir. ${ }^{[5,7-11]}$

Kardiyovasküler hastalıkların önlenmesi ve kontrolünde ilaç uyumu önemli olmakla beraber hastaların ilaç uyumunun orta düzeyde olduğu (\%40-60) belirtilmektedir. ${ }^{[3,7,12]}$ Al-Ganmi ve arkadaşlarının yapmış olduğu bir araştırmada KVH'ı olan bireylerin yarıya yakınının ilaç tedavisine yüksek uyum gösterdiği belirlenmiştir. ${ }^{[13]}$ Kardiyovasküler hastalıkların önlenmesi ve kontrolünde ilaçların yaşam boyu kullanılması gerekmektedir. Reçete edilen ilaçların düzenli kullanılmaması kardiyak fonksiyonlar ve semptomlarda kötüleşme, kan basıncı kontrolünde yetersizlik, tekrarlı hastane yatışlar ve mortalitede artış gibi ciddi problemlerin gelişmesine neden olabilmektedir. Hastaların ilaç uyumunu arttırmada multidisipliner (hekim, hemşire, eczacı, psikolog vb) bir yaklaşım gerekmektedir. KVH'ı olan bireylerin ilaç kullanımına uyum ve etkileyen faktörler belirlenerek hasta uyumunu artırıcı stratejiler geliştirilebilir. Belirlenen sonuçlar doğrultusunda hasta/ailesi -hekim-hemşire işbirliği geliştirilerek kısa ve uzun dönemli izlem, danışmanlık ve eğitim programları geliştirilebilir. Geliştirilen bu stratejiler tekrarlı hastaneye yatışların, morbitide ve mortalitenin ve sağlık harcamalarının azalmasında önemli katkılar sağlayacaktır.

\section{Gereç ve Yöntem}

\section{Araştırmanın Amacı ve Tipi}

$\mathrm{Bu}$ araştırma, $\mathrm{KVH}$ tanısıyla yatarak tedavi gören hastaların ilaç tedavisine uyumları ve etkileyen faktörleri belirlemek amacıyla tanımlayıcı olarak plandı ve uygulandı.

\section{Araştırmanın Evreni ve Örneklemi}

Araştırmanın evrenini 13 Haziran-28 Ekim 2015 tarihleri arasında KVH tanısı nedeniyle bir üniversite hastanesinin kardiyoloji servisinde yatarak tedavi gören 530 hasta oluşturmaktadır. Araştırmanın örneklemini belirlemede popülasyonunun en iyi şekilde tahmin edebilmesi için popülasyonun en azından \%30'una (159 birey) ulaşılması hedeflendi. ${ }^{[14]}$ Araştırma, 13 Haziran-28 Ekim 2016 tarihleri arasında herhangi bir $\mathrm{KVH}$ tanısı nedeniyle bir üniversite hastanesinin kardiyoloji servisinde yatarak tedavi gören, en az üç aydır ilaç kullanan, fiziksel ve bilişsel sağlık düzeyleri araştırmada uygulanacak formları cevaplamaya uygun, iletişim sorunu olmayan ve çalışmaya katılmaya gönüllü 176 hasta ile gerçekleştirildi. Araştırmaya katılmaya istekli olmayan, üç aydan daha kısa süreli ilaç kullanan, soruları 
algılamasını ve iletişim kurmasını etkileyecek, ciddi bilişsel bozukluk, göğüs ağrısı, nefes darlığı, çarpıntı şikayeti olan hastalar araştırmaya alınmadı.

\section{Veri Toplama Yöntemi ve Araçları}

Veri toplama araçları: Veriler araştırmacılar tarafından oluşturulan "Anket Formu" ve "Morisky İlaç Tedavisine Uyum Ölçeği" kullanılarak toplandı.

Anket formu: herhangi bir KVH tanısıyla yatarak tedavi gören hastaların ilaç tedavisine uyumları ve etkileyen faktörleri belirlemek amacıyla literatür taraması sonucu oluşturuldu. ${ }^{[3,6,7,12,15]}$ Bu form; $\mathrm{KVH}^{\prime}$ ı bulunan bireylerin ilaç kullanımına uyumu etkileyebileceği düşünülen bazı sosyodemografik özelliklerine (Yaş, cinsiyet, medeni durum vb.), klinik özelliklerine (yatış tanısı, ilave kronik hastalıklar, ilaç sayısı, ilaç kullanma süresi vb.) ve sağlık davranışlarına ilişkin (sigara ve alkol kullanımı, düzenli sağlık kontrolüne gitme) soruları içermekte ve toplam 23 sorudan oluşmaktadır.

Morisky ilaç tedavisine uyum ölçeği: Hasta bildirimine dayalı ve ilaç kullanım davranışlarını sorgulayan bir öz-değerlendirme ölçeğidir. Morisky ve arkadaşları tarafından geliştirilen ölçeğin Türkçe geçerlilik ve güvenirlik çalışması Hacıhasanoğlu ve arkadaşları tarafından yapılmış ve cronbach's alfa değeri 0.79 olarak bulunmuştur. ${ }^{[16,17]}$ Sekiz maddeden oluşan ölçeğin ilk yedi sorusu evet hayır şeklinde cevaplanırken 8 . soruda 5 seçenekli likert tipi şeklinde cevaplar yer almaktadır. Ölçekten alınan toplam puanın 8 olması yüksek uyumu, 6-7 puan orta uyumu gösterirken 6'dan az puan ise düşük uyumu göstermektedir. ${ }^{[16,17]}$ Ölçeğin bu araştırmadaki cronbach's alfa değeri 0.77 olarak bulundu.

Veri toplama yöntemi: Araştırma verileri hastalara araştırmanın amacı ve süresi açıklandıktan sonra araştırmayı kabul eden bireylerden yüz yüze görüşme yöntemi ile toplandı. Veri toplama formlarının uygulanması ortalama 10 dakika sürdü.

\section{Araştırmanın Etik Boyutu}

Araştırmanın yapılabilmesi için Klinik Araştırmalar Etik Kurulu'ndan etik onay (B.08.6.YÖK.2.ME.0.05.0.07.00/03), araştırmanın yürütülebilmesi için ilgili üniversitenin başhekimliğinden yazılı izin alındı. Araştırmayı kabul eden hastalar Helsinki Bildirgesi doğrultusunda, çalışmanın amacı, veri toplama işleminin nasıl yapılacağı ve ne kadar süreceği hakkında bilgilendirildi ve sözlü onamları alındı.

\section{Araştırma Verilerinin Değerlendirilmesi}

Sürekli ölçümlere ait normallik kontrolleri Shapiro Wilk testi ile test edildi. Sosyo demografik özellikler bakımından ölçek puanları arasındaki farklılıklar için Student $t$ testi ve
One Way ANOVA testi kullanıldı. Varyansların homojenliği için Levene testinden yararlanıldı. Tanımlayıcı istatistikler olarak ortalama ve standart sapma değerleri verildi. Sürekli ölçümler arasındaki ilişki için Pearson korelasyon katsayısı kullanıldı. İstatistik anlamlılık olarak $\mathrm{p}<0.05$ olarak alındı.

\section{Araştırmanın Sınırılıkları}

Araştırmadan elde edilen verilerin sadece çalışmanın yapıldığı hastaneye genellenebilmesi örneklem sayısının az olması çalışmanın en önemli sınırlılıklarındandır.

\section{Bulgular}

Araştırma kapsamına alınan bireylerin \%51.7'sinin erkek olduğu, çoğunluğunun 60 yaşın üzerinde ve çalışmadığı, $\% 56.8$ 'inin evli, \%38.1'inin okuryazar/ilkokul eğitim düzeyinde, \%50.6'sının gelir durumunun orta seviyede olduğu ve yaş ortalamalarının $65.39 \pm 7.73$ olduğu belirlendi (Tablo 1). Araştırmaya dahil edilen bireylerin $\% 64.8^{\prime}$ inde hipertansiyon (HT), \%60.8'inde kalp yetersizliği (KY) ve \%51.1'inde ise koroner arter hastalığı (KAH) bulunduğu tespit edildi. Araştırmada bireylerin yarısında ilave kronik hastalık olarak diyabetes mellitus (DM) tanısı olduğu ve yarıya yakınının (\%47.2) 5 kez ve üzeri hastaneye yattığı belirlendi (Tablo 1). Araştırmada bireylerin ilaç kullanımına ilişkin özellikleri incelendiğinde, yarıya yakınının (\%47.7) 7 ve üzeri yıldır ilaç kullandığı, yarıdan fazlasının (\%56.3) ise günde 6 ve üzeri sayıda ilaç kullandığı belirlendi. Bireylerin kullandıkları ilaçların \%79.0'unun antikoagülan, antitrombositik kullandığı, \%66.5'inin Beta-bloker ve \%65.9'unun diüretik kullandığı saptandı. Araştırma kapsamına alınan bireylerin \%62.5'inin kullandıkları ilaca yönelik düzenli kontrole gittikleri, \%40.9'unun reçete dışı ilaç kullandıkları, reçete dışı ilaç olarak ise en çok analjezik kullandıkları belirlendi. $\mathrm{Bu}$ araştırmada bireylerin \%31.8'inin yüksek, \%18.8'inin orta, \%49.4'ünün ise ilaç tedavisine düşük uyum gösterdiği ve Morisk Illaç Tedavisine Uyum puan ortalamalarının 4.78 \pm 2.03 (düşük düzeyde) olduğu tespit edildi (Tablo 2).

Araştırmaya dahil edilen hastaların sosyodemografık ve klinik özellikleri açısından ilaç tedavisine uyumları arasında önemli fark bulunmadı ( $p>0.05$ ) (Tablo 3).

Tablo 4 genel olarak incelendiğinde hastaların kullandıkları ilaçlardan en çok kalsiyum kanal blokerleri (\%83.1), antihiperlipidemikleri (\%65.6) ve antiaritmikleri (\%63.6), en az ise kalp glikozitleri (\%10.6) ve beta-blokerleri (\%22.2) neden kullandıklarını bildikleri belirlendi. Yine araştırmamızda hastaların çoğunluğunun kullandıkları ilaçların yan etkilerini bilmedikleri, yan etkilerini bilme oranı en az olan ilaç grubunun sırasıyla; kalp glikozitleri (\%0), beta-bloker (\%7.7) ve ACEil (\%8.5), diüretikler (\%12.1) olduğu saptandı (Tablo 5). 


\begin{tabular}{|c|c|c|}
\hline Özellikler & $\mathbf{n}$ & $\%$ \\
\hline \multicolumn{3}{|l|}{ Cinsiyet } \\
\hline Kadın & 85 & 48.3 \\
\hline Erkek & 91 & 51.7 \\
\hline \multicolumn{3}{|l|}{ Yaş } \\
\hline$\leq 60$ & 55 & 31.2 \\
\hline $61-70$ & 86 & 48.9 \\
\hline$\geq 71$ & 35 & 19.9 \\
\hline \multicolumn{3}{|l|}{ Eğitim durumu } \\
\hline Okuryazar değil & 35 & 19.9 \\
\hline Okuryazar/ Illkokul & 67 & 38.1 \\
\hline Ortaokul/ Lise & 58 & 33.0 \\
\hline Yüksekokul ve üstü & 16 & 9.0 \\
\hline \multicolumn{3}{|l|}{ Çalışma durumu } \\
\hline Çalışıyor & 23 & 13.1 \\
\hline Çalışmıyor & 153 & 86.9 \\
\hline \multicolumn{3}{|l|}{ Medeni durum } \\
\hline Evli & 100 & 56.8 \\
\hline Bekar & 76 & 43.2 \\
\hline \multicolumn{3}{|l|}{ Gelir durumu } \\
\hline İyi & 12 & 6.8 \\
\hline Orta & 89 & 50.6 \\
\hline Kötü & 75 & 42.6 \\
\hline \multicolumn{3}{|l|}{ Yaşadığı yer } \\
\hline Köy & 25 & 14.2 \\
\hline İlçe & 51 & 29.0 \\
\hline Şehir & 100 & 56.8 \\
\hline \multicolumn{3}{|l|}{ Beden Kitle İndeksi } \\
\hline $18.25-24.9$ & 51 & 29.0 \\
\hline $25-29.9$ & 87 & 49.4 \\
\hline$\geq 30$ & 38 & 21.6 \\
\hline \multicolumn{3}{|c|}{ Mevcut kardiyovasküler hastalıklar* } \\
\hline Hipertansiyon & 114 & 64.8 \\
\hline Kalp Yetersizliği & 107 & 60.8 \\
\hline Koroner Arter Hastalığı & 90 & 51.1 \\
\hline Ritim Bozuklukları & 4 & 2.3 \\
\hline \multicolumn{3}{|l|}{ İlave kronik hastalıklar* } \\
\hline Diyabetes Mellitus & 86 & 50.9 \\
\hline $\mathrm{KOAH}$ & 25 & 14.8 \\
\hline Böbrek Yetersizliği & 18 & 10.6 \\
\hline Diğer $^{\dagger}$ & 40 & 23.7 \\
\hline \multicolumn{3}{|l|}{ Alkol } \\
\hline Kullanıyor & 10 & 5.7 \\
\hline Kullanmıyor & 166 & 94.3 \\
\hline \multicolumn{3}{|l|}{ Sigara } \\
\hline Kullanıyor & 12 & 6.8 \\
\hline Kullanmıyor & 164 & 93.2 \\
\hline \multicolumn{3}{|l|}{ Hastaneye yatış sayısı } \\
\hline$\leq 2$ & 18 & 10.2 \\
\hline $3-4$ & 75 & 42.6 \\
\hline$\geq 5$ & 83 & 47.2 \\
\hline \multicolumn{3}{|c|}{ Düzenli sağlık kontrolüne gelme durumu } \\
\hline Evet & 110 & 62.5 \\
\hline Hayır & 66 & 37.5 \\
\hline
\end{tabular}

*Birden fazla seçenek işaretlenmiştir. ${ }^{\dagger}$ Diğer (Kanser, Alzheimer, Astım).
Tablo 2. Bireylerin ilaç kullanımına ilişkin özelliklerine göre dağılımları $(n=176)$

Özellikler $\quad$ n $\quad \%$

İlaç kullanım süresi (yıl)

$\begin{array}{lll}1-3 & 15 & 8.5\end{array}$

$\begin{array}{lll}4-6 & 77 & 43.8\end{array}$

$\begin{array}{lll}\geq 7 & 84 & 47.7\end{array}$

Kullanılan ilaç sayısı

$\begin{array}{llll}1-3 & 6 & 3.4\end{array}$

4-5

$\geq 6 \quad 99 \quad 56.3$

Kullanılan ilaç grupları*

$\begin{array}{lll}\text { Kalp glikozitleri } & 66 & 37.5\end{array}$

$\begin{array}{lll}\text { Antiaritmikler } & 11 & 6.3\end{array}$

Antianginal ve Antiiskemikler $\quad 59 \quad 33.5$

$\begin{array}{lll}\text { Diüretikler } & 116 \quad 65.9\end{array}$

Anjiotensin dönüştürücü enzim inhibitörleri $94 \quad 53.4$

Kalsiyum kanal blokörleri $\quad 83 \quad 47.2$

$\begin{array}{lll}\text { Beta-blokerler } & 117 & 66.5\end{array}$

$\begin{array}{lll}\text { Antihiperlipidemikler } & 64 & 36.4\end{array}$

$\begin{array}{lll}\text { Antikoagülanlar, antitrombositikler } & 139 & 79.0\end{array}$

İlaca yönelik düzenli kontrole gelme durumu

Hayır $\quad 66 \quad 37.5$

Reçete dışı ilaç kullanma durumu

$\begin{array}{lll}\text { Evet } & 72 & 70.9\end{array}$

Hayır $\quad 104 \quad 59.1$

Reçete dışı kullanılan ilaç isimleri*
Analjezik

$\begin{array}{lll}\text { Laksatif } & 17 & 21.5\end{array}$

$\begin{array}{lll}\text { Antibiyotik } & 16 & 20.3\end{array}$

$\begin{array}{lll}\text { Mide ilacı } & 6 & 7.6\end{array}$

Morisky Illaç Tedavisine Uyum Ölçeği
Düşük uyum

Orta uyum $\quad 33 \quad 18.8$

$\begin{array}{lll}\text { Yüksek uyum } & 56 & 31.8\end{array}$

Morisky İlaç Tedavisine Uyum düzeyi

Ortalama \pm Standart Sapma

$4.78 \pm 2.03$

*Birden fazla seçenek işaretlenmiş̧ir.

Yine araştırmamızda tüm ilaç gruplarında Morisky İlaç Tedavisine Uyum Ölçeği Puan ortalamalarının düşük düzeyde olduğu belirlendi (Tablo 5).

Tablo 5 genel olarak incelendiğinde sürekli değişkenlerin toplam puan ile aralarında doğrusal bir ilişki olmadığı ancak yaş arttıkça zayıf da olsa hem hastanede yatış sayısının arttığı $(r=0.181 ; p=0.016)$ hem de kullanılan ilaç yılının arttığı belirlendi $(r=0.340, p<0.001)$. Ayrıca, kullanılan ilaç yılı arttıkça yatış sayısının da arttığı saptandı $(r=0.272 ; p<0.001)$.

\section{Tartışma}

Kardiyovasküler hastalığı olan bireylerde ilaç uyumu hastaı̆ğın seyri açısından büyük önem taşımaktadır. İlaç tedavi- 


\begin{tabular}{|c|c|c|}
\hline & & $\begin{array}{l}\text { Morisky İlaç } \\
\text { Tedavisine } \\
\text { Uyum Ölçeği }\end{array}$ \\
\hline Özellikler & $\mathbf{n}$ & Ort $\pm S S$ \\
\hline \multicolumn{3}{|l|}{ Cinsiyet } \\
\hline Kadın & 85 & $4.8 \pm 2.1$ \\
\hline Erkek & 91 & $4.8 \pm 2.0$ \\
\hline İstatistik test ve anlamlılık & & $t=-0.158 \quad p=0.875$ \\
\hline \multicolumn{3}{|l|}{ Medeni durum } \\
\hline Evli & 100 & $4.7 \pm 1.9$ \\
\hline Bekar & 76 & $4.8 \pm 2.1$ \\
\hline İstatistik test ve anlamlılık & & $t=-0.372 \quad p=0.711$ \\
\hline \multicolumn{3}{|l|}{ Çalışma durumu } \\
\hline Çalışıyor & 23 & $5.1 \pm 2.3$ \\
\hline Çalışmıyor & 153 & $4.7 \pm 2.0$ \\
\hline İstatistik test ve anlamlılık & & $\mathrm{t}=0.861 \quad \mathrm{p}=0.390$ \\
\hline \multicolumn{3}{|l|}{ Yaşadığı yer } \\
\hline Köy/ilç̧e & 76 & $4.7 \pm 2.2$ \\
\hline Şehir & 100 & $4.8 \pm 1.9$ \\
\hline İstatistik test ve anlamlılık & & $t=-0.300 \quad p=0.764$ \\
\hline \multicolumn{3}{|l|}{ Gelir durumu } \\
\hline Kötü & 75 & $4.6 \pm 2.2$ \\
\hline Orta & 89 & $5.0 \pm 2.0$ \\
\hline İyi & 12 & $5.2 \pm 1.5$ \\
\hline İstatistik test ve anlamlılık & & $\mathrm{F}=0.816 \quad \mathrm{p}=0.444$ \\
\hline \multicolumn{3}{|l|}{ Eğitim durumu } \\
\hline Okuryazar değil & 35 & $4.8 \pm 1.9$ \\
\hline Okuryazar/ilkokul & 67 & $4.4 \pm 2.2$ \\
\hline Ortaokul/Lise & 58 & $5.3 \pm 1.8$ \\
\hline Yüksekokul ve üstü & 16 & $4.9 \pm 1.7$ \\
\hline İstatistik test ve anlamlılık & & $F=2.011 \quad p=0.114$ \\
\hline \multicolumn{3}{|l|}{ İlave kronik hastalık durumu } \\
\hline Var & 86 & $5.0 \pm 1.8$ \\
\hline Yok & 90 & $4.6 \pm 2.2$ \\
\hline İstatistik test ve anlamlılık & & $t=1.194$ \\
\hline \multicolumn{3}{|l|}{ Alkol kullanma durumu } \\
\hline Var & 10 & $5.3 \pm 1.6$ \\
\hline Yok & 166 & $4.8 \pm 2.0$ \\
\hline İstatistik test ve anlamlılık & & $t=0.816 \quad p=0.415$ \\
\hline \multicolumn{3}{|l|}{ Sigara kullanma durumu } \\
\hline Var & 12 & $4.3 \pm 2.1$ \\
\hline Yok & 164 & $4.8 \pm 2.0$ \\
\hline İstatistik test ve anlamlılık & & $t=-0.953 \quad p=0.342$ \\
\hline \multicolumn{3}{|l|}{ Düzenli kontrole gitme durumu } \\
\hline Evet & 110 & $5.0 \pm 2.0$ \\
\hline Hayır & 66 & $4.5 \pm 2.1$ \\
\hline İstatistik test ve anlamlılık & & $t=1.626 \quad p=0.106$ \\
\hline
\end{tabular}

sine olan uyumsuzluk ise hastalık belirtilerinin alevlenmesine, tekrarlı hastane yatışlarına ve sağlık harcamalarının artmasına neden olmaktadır. Bu araştırmada KVH tanısıyla yatarak tedavi gören hastaların ilaç tedavisine uyumları ve etkileyen faktörler araştırılmıştır. Araştırma sonuçları-

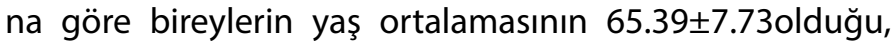
\%64.8'inde HT, \%50.9'unda DM bulunduğu belirlenmiştir. Yaşam süresinin uzaması yaşlanma süreciyle birlikte kardiyovasküler yapılar ve işlevler üzerinde meydana gelen olumsuz değişiklikler nedeniyle yaşlı bireylerde KVH görülme oranı artmaktadır. Ayrıca DM gibi ilave kronik hastalıkların varlığı KVH riskini daha da artırmaktadır. ${ }^{[13,18]}$ Araştırmamızın sonuçları literatürle uyumludur. Bu araştırmada yaş ortalaması ile ilaç tedavisine uyum puan ortalaması arasında önemli bir fark saptanmamıştır. Literatür incelendiğinde yaş ile ilaç uyumu arasındaki ilişkinin karmaşık olduğu görülmektedir. Literatürde yaşın ilerlemesiyle ilaç uyumunun arttığı, ${ }^{[13,19,20]}$ genç yaşın düşük uyum ile ilişkili olduğu, ${ }^{[21-23]}$ ve yaş ile ilaç uyumu arasında fark olmadığını bildiren araştırmalar yer almaktadır. ${ }^{[24-26]} \mathrm{KVH}^{\prime \prime}$ olan bireylerin mevcut hastalıklar ve risk faktörleri nedeniyle farklı gruplarda ve çok sayıda ilaç kullanımı yaş değişkeninden bağımsız olarak ilaç uyumunun düşük olmasına neden olmuş olabilir.

Bu araştırmada hastaların \%49.4'ünün ilaç uyumunun düşük olduğu belirlenmiştir. Literatür incelendiğinde $\mathrm{KVH}^{\prime}$ ı olan bireylerin ilaç uyum düzeylerinin değişkenlik gösterdiği görülmektedir. Ülkemizde yapılan ve araştırmamız ile benzer sonuçlar elde edilen bir araştırmada KY olan hastaların \%40'ının ilaç uyumunun yüksek düzeyde olduğu bildirilmiştir. ${ }^{[27]}$ Hindistan'da yapılan bir araştırmada ise HT, KY ve $\mathrm{KAH}$ olan bireylerin ilaç uyumları sırasıyla $\% 20.8, \% 28.3$ ve $\% 32$ olarak tespit edilmiştir. ${ }^{[28]}$ Çok uluslu yürütülen ve 9 ülkeden hastaların yer aldığı bir araştırmada ise Hollanda'da \%75.9, Polonya'da \%42.4 ve Macaristan'da ise \%29.7 oranında ilaç tedavisine uyum tespit edilmiştir. ${ }^{[29]}$ Farklı popülasyonlardaki bu değişikliklerin kültürel farklılıklar, finansal nedenler, hastalıkla ilgili inançlar, hastalığın ciddiyetinin farkında olmama, sağlık profesyonelleri ile yeterli iletişim kuramama ve sosyal destek yapısının farklııı̆ından kaynaklanabileceği düşünülebilir. Ancak hem çalışmamız hem de literatür sonuçları hastaların ilaç tedavisine uyumlarının günümüzde hala yetersiz olduğunu, ilaç tedavisine uyumu artırıcı stratejilerin geliştirilmesine gereksinim duyulduğunu göstermektedir.

Araştırmada bireylerin yaşı arttıkça zayıfta olsa hem hastanede yatış sayısının hem de ilaç kullanım süresinin arttığı belirlendi. Araştırma sonuçlarımıza benzer olarak Kim ve ark. $^{[30]}$ ve Karaca ve Mert ${ }^{[31]} \mathrm{KVH}^{\prime}$ ı olan bireylerin yaşı arttıkça hastaneye yatış sayısının arttığını belirlemiştir. Araştırma sonuçlarımız literatürle benzerlik göstermektedir. Yaşın ilerlemesiyle birlikte organ ve sistem fonksiyonları azalırken kronik hastalık görülme olasılığı artmaktadır. Kronik hasta- 


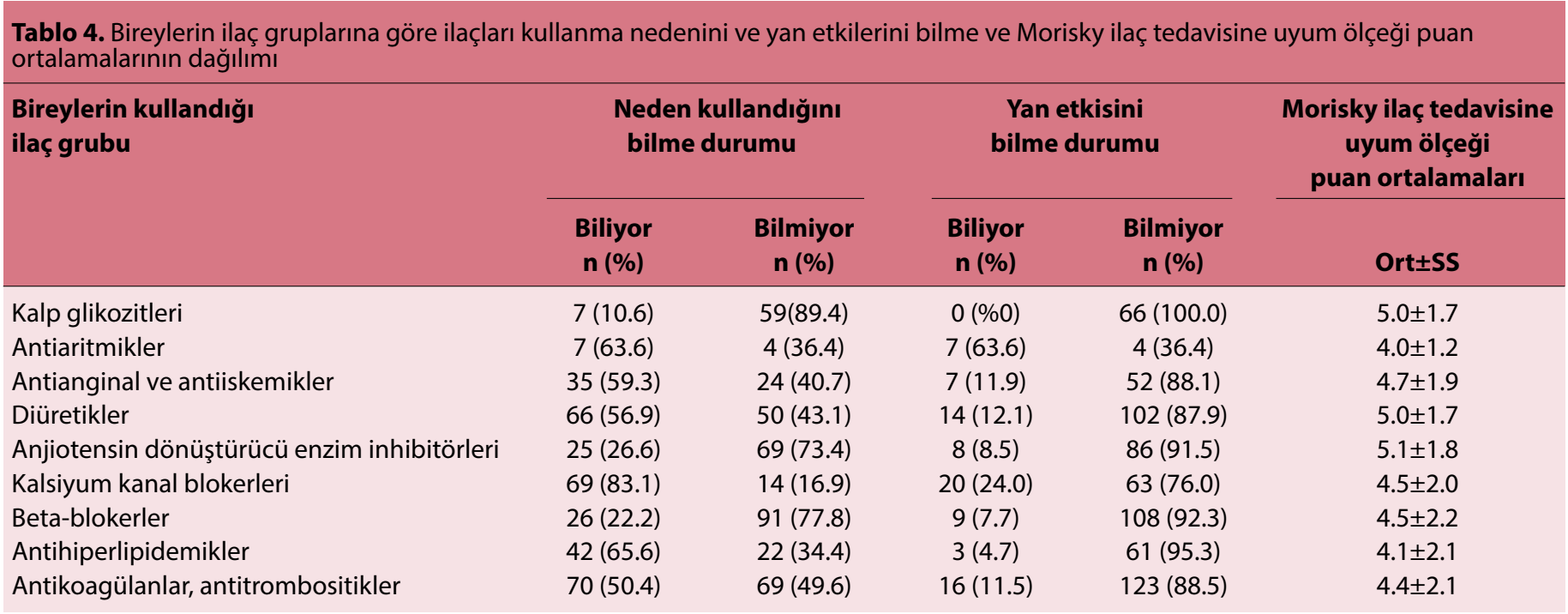

Tablo 5. Bireylerin bazı sosyodemografik ve klinik özellikleri ile Morisky ilaç tedavisine uyum puan ortalamaları arasındaki ilişki

\begin{tabular}{|c|c|c|c|c|c|}
\hline & Yaş & BKI & Kullanılan ilaç sayısı & Kullanılan ilaç yılı & Toplam puan \\
\hline & $p=0.016$ & $p=0.297$ & $p=0.527$ & $p<0.001$ & $p=0.676$ \\
\hline & & $p=0.117$ & $p=0.249$ & $p<0.001$ & $p=0.187$ \\
\hline \multirow[t]{2}{*}{ BKI } & & & $r=0.084$ & $r=0.051$ & $r=0.098$ \\
\hline & & & $p=0.267$ & $p=0.503$ & $p=0.197$ \\
\hline \multirow[t]{2}{*}{ Kullanılan ilaç yılı } & & & & & $r=-0.042$ \\
\hline & & & & & $\mathrm{p}=0.581$ \\
\hline
\end{tabular}

BKI: Beden kitle indeksi.

lık sayısı arttıkça hastaneye tekrarlı yatışlar ve kullanılan ilaç sayısı ve süresi uzamaktadır.

Araştırmaya dahil edilen bireylerin yarıya yakınının (\%47.7) 7 ve üzeri yıldır ilaç kullandığı, yarıdan fazlasının (\%56.3) ise günde 6 ve üzeri sayıda ilaç kullandığı belirlenmiştir. KVH'lar ileri yaşlarda görülmekte ve yaşam boyu tedavi gerektirmektedir. Ayrıca ileri yaşlarda KVH'la beraber ilave kronik hastaııkların varlığı nedeniyle gün içinde kullanılan ilaç sayısı da artmaktadır. ${ }^{[25]}$ Gün içinde kullanılan ilaç sayısı arttıkça hem ilaç uyumunda problemler görülmekte hem de ilaç etkileşimleri nedeniyle hastalar sorun yaşayabilmektedir. ${ }^{[18,25,32]}$ Yapılan bir araştırmada hastaların \%75'inin warfarinin etkisini arttıran ilaçların en az birini kullandıkları (antiagregan, nonsteroid antiinflamatuvar, sefalosporinleri veya metranidazol gibi) saptanmıştır. Ayrıca warfarinin etkisini arttıran ilaçlardan en az birini kullanan hastaların \%35.6'sının major kanama \%60'ının ise minör kanama nedeniyle hastaneye başvurdukları belirlenmiştir. ${ }^{[33]}$ Çoklu ilaç kullanımı bazen etkileşimler nedeniyle ciddi sağlık sorunlarını da beraberin- de getirmektedir. Bu nedenle sağlık profesyonelleri ilaç ilaç etkileşimi, ilaçların yan etkileri ve kontrolü konusunda hasta ve ailesini bilgilendirmelidir. Aksi takdirde ilacın istenmeyen etkilerini bilmeyen hasta, ilacı kullanmayı bırakabilir ya da ilacın hastalıklarının belirtilerini ortadan kaldırdığını düşünerek aşırı dozda ilaç almasına neden olabilir.

Literatürde çok sayıda ilaç kullanan hastaların ilaç uyumlarının düşük olduğunu bildiren araştırmalar ${ }^{[18,25,32]}$ olmakla beraber, kullanılan ilaç sayısı ile ilaç uyumu arasında ilişkinin olmadığını bildiren araştırmalar dabulunmaktadır. ${ }^{[13,19]}$ Bizim araştırmamızda kullanılan ilaç sayısı ve kullanım yılı ile ilaç tedavisine uyum puan ortalaması arasında istatistiksel fark çıkmamakla beraber hastaların yarısının ilaç uyum düzeyleri düşük çıkmıştır. Bu nedenle özellikle hastalara düzenli ilaç kullanmanın önemi, ilaç etkileri, yan etkileri ve ilaç etkileşimleri konusunda basit, anlaşılır eğitim verilmeli ve eğitim görsel ve yazılı materyallerle desteklenmelidir.

Bu araştırmadan elde edilen önemli sonuçlardan biri hasta- 
ların \%40.9'unun reçete dışı ilaç kullandıkları, reçete dışı ilaç olarak ise en çok analjezik ve antibiyotik (sırasıyla; \%50.6; \%20.3) kullandıklarının belirlenmesidir. Reçete dışı kullanılan ilaçların uygun olmayan miktarlarda ve sıklıkta kullanılması ilaçlara bağlı yan etki ile ilaç etkileşimleri gibi istenmeyen etkileri de beraberinde getirmektedir. Parasetamol ile warfarin arasında etkileşimi inceleyen bir araştırmada parasetamol kullanan hastalarda warfarin tedavisine başlandığında kanama riskinin 4.6 kat, warfarin kullanan hastalarda parasetamol kullanımında ise 2.7 kat arttığı saptanmıştır. ${ }^{[34]}$ Nonsteroid antiinflamatuvar ilaçların (NSAi) vücutta sodyum-su tutulumuna sebep oldukları ve antihipertansif ilaçlarla birlikte kullanıldıklarında kan basıncını arttırdıkları bilinmektedir. Dolayısıyla NSAi ve antihipertansif ilaçları bir arada kullanan hastalarda kan basıncı kontrolünün bozulmasına, kalp yetersizliği olan bireylerde ise kalbin iş yükünün artmasına neden olabilmektedir. Yapılan bir araştırmada HT hastalarında NSAI kullanımının kan basıncını arttırdığı saptanmıştır. ${ }^{[35]}$ Başka bir araştırmada ise antibiyotiklerin warfarin ile etkileşime girerek kanama riskini 2 kat arttırdığı ve bu durumun hastaneye yatış gerektirdiği belirlenmiştir. ${ }^{[36]}$ Dolayısıyla KVH'ı olan bireyler zaten çoklu ilaç kullanmaları nedeniyle ilaç etkileşimlerine yönelik sorun yaşayabilmektedir. Bunlara ilaveten reçetesiz ilaç kullanımı daha ciddi sorunların yaşanmasına, tekrarlı hastane yatışlarına hatta prognozun kötüleşmesine neden olacaktır. Bu nedenle hastalara reçete dışı ilaç kullanmanın sakıncaları ve sağlık kurumuna başvurduklarında var olan tanılarını ve kullandıkları ilaçlar konusunda hekime bilgi vermeleri özellikle vurgulanmalıdır

$\mathrm{Bu}$ çalışmada sosyodemografik ve klinik özellikler açısından ilaç tedavisine uyum puan ortalamaları arasında istatıstiksel olarak önemli fark bulunmamıştır. Bununla birlikte araştırmamızın önemli sonuçlarından biri kullanılan tüm ilaç gruplarında hastaların ilaçları neden kullandıklarını bilmemeleri (en az bilinenler sırasıyla; kalp glikozitleri \%10.6, beta-blokerleri \%22.2, ACii \%26.6) ve çoğunluğunun kullandıkları ilaçların yan etkilerini bilmedikleri (yan etkilerini bilme oranı en az olan ilaç grubu ise sırasıyla; kalp glikozitleri $0 \%$, beta-bloker \%7.7 ve ACEil \%8.5, diüretikler \%12.1) olduğunun belirlenmesidir. Yukarıda konu edilen ilaç gruplarının bradiaritmi, taşiaritmiler, elektrolit dengesizlikleri (özellikle sodyum ve potasyum dengesizliği), kanama gibi önemli yan etkileri bulunmaktadır. ${ }^{[37]}$ Hastaların ilacın etki ve yan etkileri açısından kendi kendine izlemeleri ve herhangi bir sorun çıktığında sağlık kuruluşuna başvurmaları hem kendi yaşam kaliteleri açısından hem de sağlık maliyeti açısından son derece önemlidir. Bu nedenle KVH'ı olan bireylere sağlık profesyonelleri tarafından verilen eğitimde ilaç kullanım nedenleri ve yan etkileriyle birlikte kilo takibi, hastalık belirtisi izlemi ve semptom yönetimi gibi öz bakım ve öz yönetim davranışlarını geliştirmeye yönelik eğitim ve danışmanlık verilmelidir.

\section{Sonuç}

Bu araştırmada kardiyovasküler hastalığı olan bireylerin yarısının ilaç uyumunun düşük olduğu saptandı. Ayrıca hastaların büyük çoğunluğunun ilaçları neden kullandıklarını ve yan etkilerini bilmedikleri belirlendi. Bu sonuçlar doğrultusunda KVH'ı olan bireylerin ilaç tedavisine uyumun arttırılmasına yönelik hemşireler tarafından bireyselleştirilmiş eğitim programlarının düzenlenmesi önerilmektedir.

Teşekkür: Araştırmamızın yürütülmesine katkı sağlayan ve çalışmaya katılmayı içtenlikle kabul edip bilgilerini bizimle paylaşan tüm hastalara teşekkür ederiz.

Etik Kurul Onayı: Mersin Üniversitesi Rektörlüğü Klinik Araştırmalar Etik Kurulu. Karar No: 181; tarihi: 09.06.2016.

Hakem Değerlendirmesi: Dış bağımsız.

Çıkar Çatışması: Yazarlar arasında herhangi bir çıkar çatışması bulunmamaktadır.

Yazarlık Katkıları: Konsept: M.G.; Dizayn: M.G., A.A.; Veri Toplama veya İşleme: A.A.; Analiz veya Yorumlama: S.E.; Literatür Arama: M.G., A.A.; Yazan: M.G., A.A.

\section{Kaynaklar}

1. Türkiye İstatistik Kurumu. Ölüm Nedeni İstatistikleri 2018. Available at: https://tuikweb.tuik.gov.tr/PreHaberBultenleri. do?id=30626.

2. Benjamin EJ, Blaha MJ, Chiuve SE, Cushman M, Das SR, Deo $\mathrm{R}$, et al. Heart Disease and Stroke Statistics-2017 Update: A Report From the American Heart Association. Circulation 2017;135(10):e146-e603. [CrossRef]

3. Naderi SH, Bestwick JP, Wald DS. Adherence to drugs that prevent cardiovascular disease: meta-analysis on 376,162 patients. Am J Med 2012;125(9):882-7. [CrossRef]

4. Traylor AH, Schmittdiel JA, Uratsu CS, Mangione CM, Subramanian U. Adherence to cardiovascular disease medications: does patient-provider race/ethnicity and language concordance matter? J Gen Intern Med 2010;25(11):1172-7. [CrossRef]

5. Kronish IM, Ye S. Adherence to cardiovascular medications: lessons learned and future directions. Prog Cardiovasc Dis 2013;55(6):590-600. [CrossRef]

6. Zhao S, Zhao H, Wang L, Du S, Qin Y. Education is critical for medication adherence in patients with coronary heart disease. Acta Cardiol 2015;70(2):197-204. [CrossRef]

7. Chowdhury R, Khan H, Heydon E, Shroufi A, Fahimi S, Moore $C$, et al. Adherence to cardiovascular therapy: a meta-analysis of prevalence and clinical consequences. Eur Heart J 2013;34(38):2940-8. [CrossRef]

8. Shin S, Song H, Oh SK, Choi KE, Kim H, Jang S. Effect of antihypertensive medication adherence on hospitalization for cardiovascular disease and mortality in hypertensive patients. 
Hypertens Res 2013;36(11):1000-5. [CrossRef]

9. Heisler M, Choi H, Rosen AB, Vijan S, Kabeto M, Langa KM, et al. Hospitalizations and deaths among adults with cardiovascular disease who underuse medications because of cost: a longitudinal analysis. Med Care 2010;48(2):87-94. [CrossRef]

10. Rasmussen JN, Chong A, Alter DA. Relationship between adherence to evidence-based pharmacotherapy and longterm mortality after acute myocardial infarction. JAMA 2007;297(2):177-86. [CrossRef]

11. Roebuck MC, Liberman JN, Gemmill-Toyama M, Brennan TA. Medication adherence leads to lower health care use and costs despite increased drug spending. Health Aff (Millwood) 2011;30(1):91-9. [CrossRef]

12. Kyanko KA, Franklin RH, Angell SY. Adherence to chronic disease medications among New York City Medicaid participants. J Urban Health 2013;90(2):323-8. [CrossRef]

13. Al-Ganmi AHA, Al-Fayyadh S, Ali MBHA, Alotaibi AM, Gholizadeh L, Perry L. Medication adherence and predictive factors in patients with cardiovascular disease: A comparison study between Australia and Iraq. Collegian 2019;26(3):355-65.

14. Blanche MT, Durrheim K, Painter D. Research in Practice Applied Methods for Sociel Sciences. South Africa: University of Cape Town Press Ltd. 2006

15. Rodriguez F, Cannon CP, Steg PG, Kumbhani DJ, Goto S, Smith $\mathrm{SC}$, et al; REACH Registry Investigators. Predictors of long-term adherence to evidence-based cardiovascular disease medications in outpatients with stable atherothrombotic disease: findings from the REACH Registry. Clin Cardiol 2013;36(12):721-7.

16. Morisky DE, Ang A, Krousel-Wood M, Ward HJ. Predictive validity of a medication adherence measure in an outpatient setting. J Clin Hypertens (Greenwich) 2008;10(5):348-54. [CrossRef]

17. Hacıhasanoğlu Aşılar R, Gözüm S, Çapık C, Morisky DE. Reliability and validity of the Turkish form of the eight-item Morisky medication adherence scale in hypertensive patients. Anadolu Kardiyol Derg 2014;14(8):692-700. [CrossRef]

18. Gelchu T, Abdela J. Drug therapy problems among patients with cardiovascular disease admitted to the medical ward and had a follow-up at the ambulatory clinic of Hiwot Fana Specialized University Hospital: The case of a tertiary hospital in eastern Ethiopia. SAGE Open Med 2019;7:2050312119860401.

19. Gavrilova A, Bandere D, Rutkovska I, Šmits D, Mauriņa B, Poplavska E, et al. Knowledge about Disease, Medication Therapy, and Related Medication Adherence Levels among Patients with Hypertension. Medicina (Kaunas) 2019;55(11):715.

20. Mukora-Mutseyekwa FN, Chadambuka EM. Drug adherence behavior among hypertensive out-patients at a tertiary health institution in Manicaland province, Zimbabwe, 2011. Patient Prefer Adherence 2013;7:65-70. [CrossRef]

21. Lee GK, Wang HH, Liu KQ, Cheung Y, Morisky DE, Wong MC. Determinants of medication adherence to antihypertensive medications among a Chinese population using Morisky Medication Adherence Scale. PLoS One 2013;8(4):e62775.

22. Khan MU, Shah S, Hameed T. Barriers to and determinants of medication adherence among hypertensive patients atten- ded National Health Service Hospital, Sunderland. J Pharm Bioallied Sci 2014;6(2):104-8. [CrossRef]

23. Teshome DF, Bekele KB, Habitu YA, Gelagay AA. Medication adherence and its associated factors among hypertensive patients attending the Debre Tabor General Hospital, northwest Ethiopia. Integr Blood Press Control 2017;10:1-7. [CrossRef]

24. Jankowska-Polańska B, Uchmanowicz I, Dudek K, Mazur G. Relationship between patients' knowledge and medication adherence among patients with hypertension. Patient Prefer Adherence 2016;10:2437-2447. [CrossRef]

25. Awad A, Osman N, Altayib S. Medication adherence among cardiac patients in Khartoum State, Sudan: a cross-sectional study. Cardiovasc J Afr 2017;28(6):350-5. [CrossRef]

26. Kamran A, Sadeghieh Ahari S, Biria M, Malepour A, Heydari H. Determinants of Patient's Adherence to Hypertension Medications: Application of Health Belief Model Among Rural Patients. Ann Med Health Sci Res 2014;4(6):922-7. [CrossRef]

27. Köseoğlu N, Enç N. Kronik Kalp Yetersizliği Olan Bireylerde Illaç Uyumuna Engel Olan Faktörlerin İncelenmesi. Turk J Card Nur 2016;7(14):162-8. [CrossRef]

28. Santra G. Assessment of adherence to cardiovascular medicines in rural population: An observational study in patients attending a tertiary care hospital. Indian J Pharmacol 2015;47(6):600-4. [CrossRef]

29. Morrison VL, Holmes EA, Parveen S, Plumpton CO, Clyne W, De Geest $S$, et al. Predictors of self-reported adherence to antihypertensive medicines: a multinational, cross-sectional survey. Value Health 2015;18(2):206-16. [CrossRef]

30. Kim HL, Lee SH, Kim J, Kim HJ, Lim WH, Seo JB, et al. Incidence and Risk Factors Associated With Hospitalization for Variant Angina in Korea. Medicine (Baltimore) 2016;95(13):e3237.

31. Karaca S, Mert H. Kalp yetersizliği olan hastaların hastaneye tekrar yatış sıklığı ve nedenlerinin incelenmesi. Anadolu Hemşirelik ve Sağlık Bilimleri Dergisi 2011;14(3):1-7.

32. Uchmanowicz B, Jankowska EA, Uchmanowicz I, Morisky DE. Self-Reported Medication Adherence Measured With Morisky Medication Adherence Scales and Its Determinants in Hypertensive Patients Aged $\geq 60$ Years: A Systematic Review and Meta-Analysis. Front Pharmacol 2019;10:168.

33. Alay M, Demir C, Atmaca M, Esen R, Dilek İ. Oral Antikoagülan Tedavi Seyrinde Kanama Komplikasyonu ile Gelen Hastaların Değerlendirilmesi. Van Tıp Dergisi 2011;18(1):9-14.

34. Launiainen T, Sajantila A, Rasanen I, Vuori E, Ojanperä I. Adverse interaction of warfarin and paracetamol: evidence from a post-mortem study. Eur J Clin Pharmacol 2010;66(1):97-103.

35. Aljadhey H, Tu W, Hansen RA, Blalock SJ, Brater DC, Murray MD. Comparative effects of non-steroidal anti-inflammatory drugs (NSAIDs) on blood pressure in patients with hypertension. BMC Cardiovasc Disord 2012;12:93. [CrossRef]

36. Baillargeon J, Holmes HM, Lin YL, Raji MA, Sharma G, Kuo YF. Concurrent use of warfarin and antibiotics and the risk of bleeding in older adults. Am J Med 2012;125(2):183-9. [CrossRef]

37. İgnatavicius DD, Workman ML. Medical Sorgical Nursing: patient Centered Colobrative Care. $8^{\text {th }}$ Eds., Elsevier; 2016. 